\title{
Employee Training and Its Effect on Employees' Job Motivation and Commitment: Developing and Proposing a Conceptual Model
}

\author{
Sadaf Zahra ${ }^{1}$, Amna Iram ${ }^{1}$, Hummayoun Naeem ${ }^{2}$ \\ ${ }^{1}$ Army Public College of Management \&Sciences, Ordnance Road, Rawalpindi, Pakistan) \\ ${ }^{2}$ Foundation University, Institute of Management and Computer Sciences, New Lalazar, Rawalpindi, Pakistan)
}

\begin{abstract}
In this competitive and rapidly changing era, most of the business organizations are highly concerned to provide their employees with training throughout their careers so that they will remain enough motivated and focused to their work. But the success of any training program depends on effective construction of its pre-defined schedule or model. The training model must be constructed on the basis of particular training needs and consisted of all relevant and important steps which are to be followed by training sessions. Wrong development of model and missing of any important step can leads towards ineffective and useless consequences. This article is based on the analysis of eight training models. The purpose of reviewing these models is to discuss the similarities, differences and lacking steps among these models so that researchers could make another new effective training model by including these missing steps. After in depth analysis of these models, researchers have proposed a more comprehensive training model for corporate world to overcome the missing. This is a simple but detailed model which, if implemented properly could contribute a lot towards enhancing both the employees' performance and effectiveness of the organization as a whole.
\end{abstract}

Keywords: Objectives Alignment,Organizational Effectiveness, Skillful Workforce, Training Evaluation, Training Models.

\section{Introduction}

Every organization is facing many challenges regarding changed nature of work and workplace environment due to technological advancement or any other factor. This rapid change requires competent, efficient, skillful, flexible and knowledgeable workforce for attainment of organizational goals and long term profitability. For developing such skills and competencies in employees, training plays a vital role along with motivation and encouragement. Training is getting more important day by day to many companies for their survival, their growth and to get competitive advantage among competitors. Training provides help to growth of the organization as its various departments' survival relies on training. Both the employees' and organizational goals are affected by training outcomes and it is considered as an important and necessary human resource practice that can impact on organization's success.

In most of the cases training is considered for new employees only, it is good to invest more on development of their skills so that they can increase their productivity. But ongoing training of current employees is as important as of new employees; it helps them to adapt their daily routine work according to rapidly changing job requirementsand to improve their performance on current job and prepares them for an intended job. And it also helps reducing resistance to change among employees. For making training process purposeful and successful company leaders should work closely with functional department heads and Human Resources personnel to follow a systematic approach to training and to get desired and fruitful outcomes from it [1].

Mainly organizations go for training programs to improve productivity and quality, to increase organizational and employee morale, to motivate employees, to achieve financial gains, for prevention from industrial accidents, to provide wider awareness to employees that leads them to enhance their personal growth, to reduce employees' turnover intentions, for enhancement of company's image through conducting ethics training and for updating employees skills to align them with company's goals and objectives[2].

Through training employees' need for supervision gets decreased and they can make better decisions on their own and involved in effective problem solving. Training gives basis to personal development by helping employees to develop leadership talent and communication skills, it decreases their fear in attempting new tasks and enables them to handle stress, frustration and conflicts. These factors give them a chance to perform better which result in developing feelings of satisfaction towards their job.Training develops required talents and capabilities in employees which ensure that each and every employee can give contribution towards organization's strategic objectives.

As the more financial gains and high profitability are the major objectives of any business development organization, the heads emphasize on proper training of employees conducting by the right person having capability to transfer conceptual knowledge to participants. They spend money, time, efforts and their resources 
on effective training prior to involve their employees in practical work instead of getting loss in their business and then conduct training to rectify problems. Instead of focusing only on how to improve satisfaction level, it is important to emphasize on helping employees to become more productive [3].

Training decisions are based on company's business strategies and objectives; training strategy must always align with company's strategy through whichtraining needs can be identified. It can be identified through analysis of whole organization (current status of company and future targets), specific job characteristics and the needs of individual employee (whether they have abilities to perform required tasks or not).Training need analysis can be done through various methods like surveys, questionnaires, observations and also internal audit gives help to point out areas that need training. By gap analysis betweenemployees' current performance and desired level of performance, objectives of training get finalized to evaluate the training program. Then selection of right trainer has importance to make thetraining program successful and more beneficial for needs fulfillment. Training methods are selected according to the types (on the job, off the job), needs and participants of training. These methods include: orientations, job instruction training, internships, job rotation, coaching, lectures, discussions, case studies, role playing, simulation and laboratory training. After conducting training: timely evaluation is done; feedback is taken from both trainers and trainees, if there is still any deficiency in employees skills or objectives of training couldn't achieve successfully then again planning step and setting objectives for further training by making required adjustments repeated to become it more effective unless company achieve its desired outcome from training.

Business success is based on many factors like to have more finances for production and growth, to develop innovative ideas for business promotion and for getting competitive advantage, to make effective strategies, to have high employee loyalty and the most important to have competent, skillful and motivated workforce. These skills, competencies, knowledge and motivation can be enhanced through training [4]. As every industry has its own vision, mission, objectives, strategies, types of business involved, ways of getting work done, employees having specific skills to perform desired task and also separate competitors so different companies set different ways and programs to train their employees. Mainly training zone developed within human resource (HR) department, HR people involved in training and development of employees. They conduct training programs whenever any department head demands training of his/her employees, they then follow the proper predefined procedure of training. For setting predefined steps of training, HR training zone heads integrate with leaders and functional departments' heads to develop the training models according to their specific needs. These models are updated regularly according to changed needs; they are helpful in conducting training programs fast and in time and also prevent wastage of time. Every organization has its own training models depend upon their needs and objectives.

This study emphasize on reviewing the different training models of various business industries and models which are designed and proposed by various scholars are also included. Their steps and procedures, similarities, differences and lacking of steps are discussed. And development of new and effective training model which could help various industries to follow itstraining stepsefficiently is also considered to become their training programs more purposeful and their employees more committed, satisfied, skillful and empowered.

\subsection{Problem statement}

Employee training is becoming an important factor for organizations' success world over. The costs of employee training are high but of course these costs are far lesser than high profits which can be achieved through proper training. Most of the companies are encountered many problems regarding their employees like absenteeism, turnover, lack of commitment, motivation and capabilities, having insufficient knowledge and skills etc. These problems arise because of overall absence of training, ineffective training programs, fail to plan training and develop its model and also fail to implement the modelin training programs. Most of our organizations do not go for their employees' training and almost no studies have been carried outon determining of various training models and then proposing a new model for organizational assistance.

Hence our problem statement becomes as: How to develop an effective model for employee training leading to better outcomes through high job motivation and commitment.

\subsection{Objectives of the Study}

The objectives of this study are:

- To study different training models of various organizations and by different scholars to come up with better understanding of their steps and procedures and also to notify similarities, differences and lacking among them.

- To develop our own effective training model in the light of understanding of different selected models which can be helpful for various training zones of HR departments to enhance their employees' job motivation and commitment. 
- To recommend some techniques to develop a purposeful training model and its implementation throughout the training program.

\subsection{Significance of the study}

This study will contribute to the literature on developing training models for better growth in many ways.

- Firstly, it will use a thorough study of various training models to get better understanding of steps involved and to make comparison among them.

- Secondly, after doing thorough study it will give insight to various techniques that must be considered while developing a training model and what steps of training are to be used for what type of industry.

- Thirdly, this study will provide a basis to make amendments in training models to improve its effectiveness for employees' and organizational benefits.

- The new model of the study can be used by various HR departments which can be used in enhancing the quality of training programs to give rise to more satisfied, motivated and committed employees.

\section{Literature Review}

In this new era of learning and development, organization's success mainly depends upon continuous performance improvement through hiring the right person for doing the right job, creating and enhancing quality products and processes, reducing cost and all other positive aspects of the organization are also involved in enhancing performance [5]. According to various authors, training is considered to be a vital activity in order to have well qualified, flexible and well prepared workforce to achieve the higher standards of performance. Employee training promotes a learning culture, reduces resistance to change, develops decision making skills and involves employees actively in the process of decision making rather than to give only new knowledge, skills and abilities to employees [6].

Considering the importance and need of training is not only important but it is also necessary to know that what kind and how much of training is required for a particular job need. Inconsidering this, one needs to determine who should be trained, what areas of training should be covered, what methods and resources can be used and who should conduct the training [7]. [7] Also added that the image of a company rises to peak when an employee becomes able to implement the skills successfully in his practical work which he has acquired from training. Only those organizations can achieve high performance and satisfaction both in the short and long term which invest heavily in their employee development and training programs.

It is important to consider that development and implementation of training procedures, systems and strategies must align with the organizational needs and strategies to accomplish business objectives [8]. To achieve the real purpose of training process and to make it systematic, it is very important that company leaders must integrate with functional departmental heads and Human Resources personnel for planning[6]. [9] Contributed thatthe training objectives usually clear what goals and objectives are required to be accomplished at the end of the training program. While delivering an employee training and development program it must be kept in mind that its success mainly depends upon its proper execution and development of methods to identify training needs that mustalign with organizational goals. If training is conducted specially to achieve specific corporate goals then any financial considerations resulting from the training act like an investment in the prolonged existence of any business [10].

Employees provide variety of skills, knowledge and talents to a company and they consider the most important and useful asset of any company, so organizations are needed to retain such human asset by keeping them motivated through effective trainings for further development and to enhance their skills for betterment and success of the company [11]. Heavy investment of time, effort and money in training process promotes employee commitment towards organizational goals. Employees through training programs usually report higher levels of commitment to their job and are less likely to have turnover intentions [12]. Organizations, in which their employees support and value the training programs, are able to achieve greater commitment outcomes [13]. Management behavior is also one of the most important determinants of successful training programs. Employee commitment is higher in those organizations where management allows access to and supports employee training [14].

To fully understand the training process and how it can be conducted effectively, it is essential to determine training models by various organizationsand developed by various researchers and scholars. Such models would not only provide a foundation for more in depth research in employee training, but they also contribute greatly to preparation of training models for better training outcomes. There are a few comprehensive models of employee training. For example, [15]developed a well-known and widely used four-level training evaluation model. [16] Also proposed an integrated model of motivational influences on training effectiveness.[17] Then built a model of training transfer. Based on[15]'s model, [7]produced an enhanced three-level training evaluation model. Later, [18]developed an integrated model of training motivation based on a meta-analytic path analysis of related research in the last 20 years. 


\section{Methodology}

This study is qualitative in nature and used secondary sources like journals, booksand internet web pages to collect different training models. By thorough analysis of steps and procedures of these models and similarities, differences and lacking among these models, a new training model is developed for corporate world to make further enhancement in the field of training processes and programs.

\section{Discussion}

Training helps to develop overall personality of employees by making them more productive through developing the sense of team work. Quality of work and work life can be increased through effective training which helps in developing good image of organization. Training also boosts up the morale of workforce which is the most important factor of getting high profits. Employees get motivated through training as they get clarity about their roles, boundaries and expectations from them, they know very well about what to do in which situation or circumstances. Less or no supervisory support is required to trained employees as training develops decision making and problem solving skills in them so theycan easily adapt their daily routine work to empowerment whenever their supervisors give this opportunity to them. Training also helps to develop mutual trust and understanding between supervisors and their subordinates. In both cases, when employee is new and the system is new, training plays an important role in adjustment.

As training is a systematic process, so it follows some defined steps for its completion. These systematic steps together form a model or training cycle to be followed by various organizations. As discussed earlier, every organization designs its own training model according to its needs, requirements and nature of jobs involved.These models help employers that how they can place their training programs successfully on a steady path of continuous improvement and how they can use training evaluation results to improve future programs. By giving systematic steps, these models also provide guidance in cost reduction of training programs.In this study we reviewed training models of different organizations andalso those models which are designed or purposed by various scholars in their publications. These models are simple, clear and easy to understand and can be followed by various training and learning managers, human resource managers, organizational development managers, performance improvement managers, training coordinators(designers and evaluators) and trainers/facilitators if their needs and demands match with the particular needs for which these models are designed.

\subsection{Analysis of Various Training Models}

For this study of training models, following eight models are selected for reviewing.

1.1.1 System modelby [19].

1.1.2 Instructional system development modelby [19].

1.1.3 Transitional modelby [19].

1.1.4 Training cycle for magistratesby [20].

1.1.5 Model of the training process by [21].

1.1.6 The process of learning model by [22].

1.1.7 The North Star eight point training modelby [23].

1.1.8 Bramley's individual model of trainingby [11].

\subsubsection{System Model}

System model consists of five steps to achieve the purpose of helping employees to perform their work to required standards. It starts with the analysis and identification of training needsand making estimation of training cost. Then in the next step training objectives are designed and developed to meet the identified needs.Afterwards, activities in the training program, delivery methods and required training materials are listed down. Then careful implementation of defined programrequired because one wrong step can lead to the failure of whole training program. Last step focuses on evaluation of each phase so as to make sure that it has achieved its aim in terms of subsequent work performance or not. Here feedback from trainers and trainees are required about effectiveness of training program andfrom supervisors and employees after few months about its real implication in practical jobs and its effects on job results. According to feedback,necessary amendments are then made to any of the previous stage in order to remedy or improve failure practices.

Source: [19]

\subsubsection{Instructional System Development Model}

This model is used to answer the training problems and it is mainlyconcerned with the training needs abouton the job performance. Training objectives are defined on the basis of job responsibilities, job descriptions and measureable standards of performance. It also comprises of five steps starts with the training need assessment, job analysis and target audience analysis. Then the planning step consists of setting goals of 
the learning outcome, types of training material, content of training and its sequence and methods of evaluation. In development phase, course material in form of handouts, workbooks and visual aids are developed. Afterwards in execution phase, it focuses on logistical arrangementslike arranging speakers, benches, lighting and other training accessories and delivery of training is there in this phase.Evaluation in the last step same as system model to identify strengths and weaknesses and to ensure that training process has achieved its objectives and to make further amendments as required. Feedback is an important phase throughout the entire training program. In this model, the output of one phase is an input to the next phase.

Source: [19]

\subsubsection{Transitional Model}

Transitional modelfocuses on the organization as a whole. This model has two loops, the outer loop of model describes the vision, mission and values of the organization and on the basis of vision, mission and values the training model which is also called inner loop of transitional model is constructed, executed and implemented. This training model consists of training objectives, planning, implementation and evaluation. The objectives are formulated on basis of these three things and then the training model is further implemented.

Source: [19]

\subsubsection{Training Cycle for Magistrates}

This model is developed to provide guidance to those people whoplan and review the training programs for magistrates. The model comprises of five steps and for performing each step some specific standards are defined to meet the needs and objectives accurately. Theinitial stage of training cycle identifies the training needs, target audience and its expected outcome and impact. Second step covers planning and designingof magistrate training. Third step is of developing, it ensures that the delivery of the training is effective and provides opportunities for the learners to learn. In this step appropriate format and different training methods are used for meeting training needs. Then in the fourth step, after delivery of training, it actually applies in the real court environment to ensure that all learning outcomes are applied and reinforced in practice within the court environment. The last step is to evaluate training program, here through practical work of magistrates training process success is evaluated. This stage deals with the collection, analysis and presentation of information to establish the improvement in the performance of learning process.

Source: [20]

\subsubsection{Model of the Training Process}

This training model also consists of five steps starting from need analysis. Then in design phase training objectives are defined and methods are examinedto determine their appropriateness for the learning objectives. Then in developing step the training methods and all activities in the training programs are finalized. Next step is to implement the training process carefully. In this model, the developer more emphasized on evaluation, it is the step which is not only considered as the last step of process but it is the main step that connects to all the remaining four steps. It means that evaluation is required at each phase to ensure its appropriateness and to take next step correctly. By this step by step evaluation, the last final evaluation may contain less failure practices.

Source: [21]

\subsubsection{The Process of Learning Model}

This model concentrates on mutual relationship between trainer and trainees and shows that training process can only be successful when efforts of both parties are involved. In the first two steps, trainer's responsibilities are high there i.e. to provide a suitable climate for learning and a structure for mutual planning. As in planning, conducting and evaluation of training process both the trainers and trainees are involved fully so this model also presents that training stepsmust be developed and planned by active participation of both the trainers and learners. These steps areto determine learners' interests, needs and values (trainees communicate their needs and interests freely), formulation of objectives, making designs for learning (use of active learning techniques), carrying out the design (encourage the active participation of trainees) and mutual evaluation; leading to reappraisal and revision of the learning objectives. And after evaluation, if there is any discrepancy in the process the training cycle again starts from determining trainees' needs phase to redesign new learning activities.

Source: [22]

\subsubsection{The North Star Eight Point Training Model}

This model is proposed to bring positive change in any workplace. This model starts with the same traditional steps of training to identify and analyze the needs of employees and organization. Then design the 
training courses with a focus to meet the specific needs of the participants. Implementation phase is considered after designing the training courses. Nowafter implementation step, this model mentions evaluation step and further three post evaluation steps after it.By observing the employee attitude and the practical implementation of knowledge gained through training in the workplace or in artificial settings, if the participants do not perform well there or they lack some abilities and skills then additional support is given to them by revisitingto training sessions and refreshing the information for participants. By following this technique if there is still any fault then again the cycle is repeated from need analysis. In this model more emphasis is on providing further assistance on regular basis after evaluation phase.

Source: [23]

\subsubsection{Bramley's Individual Model of Training}

This model focuses more on individual knowledge, skills and abilities that organization should recognize that its employees are not effective and motivated and the change is required in their knowledge, skills and abilities. After need analysis, suitable training is conducted by following the traditional steps of designing, implementing and evaluating the training program to fulfill specific needs, enhance employee willingness to participate and meet their expectations. This training then enhances the individual performance by improving their knowledge, skills and abilities. As a result, this improved performance then leads towards improvement of overall organizational performance.

Source: [11]

\subsection{Similarities}

By careful analysis and reviewing of these models, some similar steps among these models are noted down.

- Training need analysis (identification of training needs) is considered as an initial step in most of these models, it is carried out for asking question, what do we want our employees to get out of the program? A great way to complete this phase is to perform a "gap analysis" by comparing current results to the desired performance. Another way to perform this phase is to get employees' help by asking where they need help.

- Designing phase is similar step in these models, which is to be taken for setting objectives and making plans about the training program. Here decisions are taken regarding who conducts the training, type of training, methods involved, location, timings etc.

- After designing phase mostly models indicate delivery, development and implementation of training program step which ensures that the delivery of training is effective and provides opportunities for the learners to learn.

- Evaluation is considered as the last step in most of the models to ensure that required needs are fulfilled and objectives are attained. It is an important step to check the effectiveness of training program.

These are very similar steps in each and every model as they are the basic steps of training and training without them is not called as an effective and objective oriented training.

\subsection{Differences}

There are some differences in these models based on different conceptions.

- The concept of taking feedback as an ongoing process and making evaluation after completion of each and every phase rather than to emphasize on final evaluation only is not followed by all these models.

- The training steps are designed according to the organization's vision, mission and values only in Transitional Model.

- The most important responsibilities of both trainer and trainees which are necessary to conduct any training program are mentioned and separated clearly only in The process of Learning Model.

- Post evaluation steps that consider further assistance to participants are only given in the North Star Eight Point Training Model.

- Building a relationship of improved performance of individual employee with improved performance of organization through training is mentioned only in Bramley's Individual Model of Training.

\subsection{Gap Identification}

There are few steps which are missing in these models.

- After need analysis and before designing the training program, individual characteristics and organizational factors are to be considered for accurate designing and development of program.

- After designing and developing training program, there must be a step of selecting suitable trainer for specific training. Here negotiations are conducted between trainer and management about compensation and content of the training to be delivered.

- Beforetraining program is implemented, motivate learners to learn for their own and organizational benefits. 
- After conducting training, check trainees' reactions and motivate them to transfer training in their practical work.

- In evaluation phase, performance of both trainer and trainees during training are also to be considered rather only to consider the performance of trainees during and after the training.

- After evaluation, step of giving rewards and recognition to well performers either trainee or trainer is to be added.

\subsection{Developing and Proposing a Conceptual Model of Training for Corporate World}

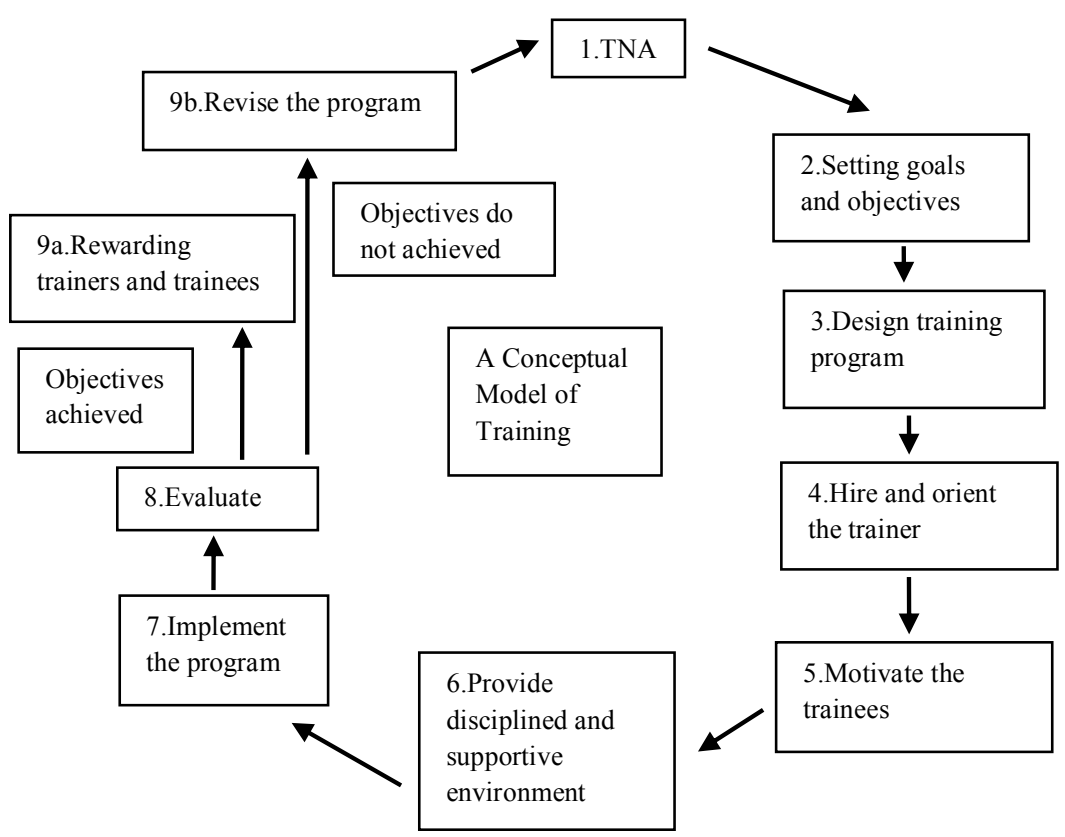

Figure: 1

\subsubsection{Training Need Assessment (TNA)}

The first step of this model is to analyze the needs of training. Training need assessment is a tool by which we determine whether any training is needed or not and what kind of training is needed and to whom. TNA is conducted by using different methods like observation, interviews, questionnaires etc.

\subsubsection{Setting Goals and Objectives}

Next step is to define the goals and objectives of the training that why we are conducting training, what outcomes will it bring to the organization and in which way it will lead to the effectiveness of organization. Setting objectives define the standards to measure the performance of trainers and trainees after conducting the training.

\subsubsection{Design Training Program}

Designing include the content of the program, what topics will be covered and what the way or tool will be used to deliver the training. Like training will be formal, informal, on the job or off the job training etc. and training will be given through lectures, case studies, role playing or simulation method.

\subsubsection{Hire and Orient the Trainer}

One of the common mistakes we do is that we don't hire a right person to conduct training and do not properly guide trainer that in which area we need training, what should be the content of training and what are the real objectives of training. This negligence can cause discrepancies in final outcomes of training. To avoid this problem we should hire the appropriate and competent person to conduct training and also giveorientation to him about main points of training and its related items.

\subsubsection{Motivate the Trainee}

Usually employees are reluctant to participate in trainings. There are many reasons of this like training centers are too far to reach over there, managers don't provide them support, or employees take it as just 
wastage of time. So employees are needed to motivate for training by guiding them that this will improve their performance at their workplace and will help them in their career development.

4.5.6 Provide Disciplined and Supportive Environment

Unless and until a very supportive and disciplined environment is there, the training is just wastage of time and money. Managers should provide full support and appropriate venue for training to their employeesso that they can actively participate in training programs.

\subsubsection{Implement the Program}

Put the plan into the action, start training actually, it means to work upon the documentation we have made for training.

\subsubsection{Evaluate}

After proper implementation of the training program, the next step is to evaluate the performance of both trainers and trainees right after the program and also observe the performance of trainees at their workplace after few months of training, that are they utilizing the techniques they learned during training. It will make us aware whether our training program has proved effective or not. By this we will come to know about the weaknesses and strengths of our training program.

\subsection{9 (a) Rewarding Trainers and Trainees}

Evaluation gives us the results of training program. If training program achieves its objectives, then we should give rewardsto trainers for their best effort and performance and these rewards must be other than thedecided compensation. For trainee these rewards may be in the form of some praising comments, certification, giving responsibility of an important project etc. These rewards motivate trainees to participate more in such type of knowledge building training programs and also perform better there.

\subsection{9 (b) Revise the Program}

If evaluation results show negativity that objectives of training do not achieved then there is need to making improvements and changing in our program. As it is a continuing and systematic process so after revising the program it again follows the same cycle.

\section{Conclusion}

- Employee training is the most suitable method to modify and manage workforce skills according to organization's objectives and to improve the overall organizations' performance.

- Organizations' performance always depend upon performance of its employees, so training also plays an important role in increasing employees' job motivation, satisfaction and commitment.

- Training is a form of investment that needs more time, effort and money but this investment gives long term benefits to both organizations and employees.

- Effectiveness of training totally depends upon effectiveness and correct implementation of its model.

- Training models save time and effort and set a direction to follow for conducting trainings.

- Training process can only be successful when participants are motivated to learn and excel their knowledge, skills and abilities.

\section{Recommendations}

- Training programs should be planned carefully by aligning the objectives of training with organizational objectives.

- Training model must be developed to fulfill the specific needs.

- Model should be developed by involvement of group of expert persons, HR professionals, specific department heads that needs training, trainers (if they hire earlier or select from within the organization) and trainees also to avoid any future conflict.

- Supportive environment should be built within organization so that employees can freely communicate with their managers about their needs towards training.

- To avoid any problem in implementation and evaluation stages, it is necessary to design and develop all training activities, materials and methods timely and accurately.

- Disciplined environment must be given for implementation of training.

- Evaluation of training should be conducted at the spot right after closing the training program by taking feedback from both trainer and trainees along with the evaluation conducted at workplaces. 
- Our proposed conceptual model is practical in usage because it facilitates the process of learning by making the content easy to understand, which provides the participants more alternatives to enhance their skills for the betterment of their careers.

\section{References}

[1] J. Clavelle. (2012).Five steps to any training process. [Online]. Available: http://www.articlesbase.com

[2] M. McDougall, and S. R. Beattie, The missing link? Understanding the relationship between individual and organizational learn ing, International Journal of Training and Development, 4, 1998.

[3] S. P. Robbins, Organizational behavior (NJ: Prentice Hall, USA, 1993).

[4] J. S. Adams, Toward an understanding of inequity, Journal of Abnormal and Social Psychology, 67(3), 1963, 422-463.

[5] B. J. Wells, H. B. Layne, and D. Allen, Management development training and learning styles, Public Productivity \& Management Review, 14, 1991, $167-176$

[6] N. Sanchez, A. Arago, B. I. Arago, and S. Valle, Effects of training on business results, International Journal of Human Resource Management, 4, 2003, $105-122$.

[7] E. F. Holton, The flawed four-level evaluation model, Human Resource Development Quarterly, 7(1), $1996,5-21$.

[8] L. Baird, and I. Meshoulam, Managing two fits of strategic human resource management, The Academy of Management Review, $13,1988,7-10$.

[9] P. Lewis, A framework for research into training and development, The International Journal of Training and Development, 3,1997, $18-26$.

[10] J. Vemic, Employee training \& development and the learning organization, Economics and Organization, 4, $2007,16-23$.

[11] J. Swart, C. Mann, S. Brown, and A. Price, Human resource development: Strategy and tactics (Elsevier Butterworth-Heinemann Publications, Oxford, 2005).

[12] P. L. Owens, One more reason not to cut your training budget: The relationship between training and organizational outcomes, Public Personnel Management, 35(2), 2006, 163-171.

[13] K. Bartlett, The relationship between training and organizational commitment: A study in the health care field, Human Resource Development Quarterly, 12(4), 2001, 335-352.

[14] J. Heyes, and M. Stuart, Does training matter? Employee experiences and attitudes, Human Resource Management Journal, 6(3), 1996, 7-21.

[15] D. L. Kirkpatrick, Evaluating training programs: The four levels (New York: McGraw-Hill, 1994).

[16] R. A. Noe, and N. Schmitt, The influence of trainee attitudes on training effectiveness: Test of a model, Personnel Psychology, 39(3), 1986, 497-523.

[17] T. T. Baldwin, and J. K. Ford, Transfer of training: A review and directions for future research, Personnel Psychology, 41(1), 1988, 63-105.

[18] J. A. Colquitt, L. J. LePine, and R.A. Noe, Toward an integrative theory of training motivation: A meta-analytic path analysis of 20 years of research, Journal of Applied Psychology, 85(5), 2000, 678-707.

[19] H. Crpatna. (2011). A project report on training and development at Sahara India. [Online]. Available: http://www.slideshare.net

[20] Judicial Studies Board. (2006). Framework of standards for magistrate training and development.[Online]. Available: http://www.jsboard.co.uk

[21] P. N. Blanchard, and J. W. Thacker, Effective training: Systems, strategies, and practices (Englewood Cliffs, NJ: Prentice Hall, 2003).

[22] D. Laird, Approaches to training and development(Addison-Wesley, Reading Mass, 1985).

[23] North Star Educational Consulting Group. (2012). The north star 8 point training model. [Online]. Available: http://www.northstaredu.net 